\title{
ENTRE DUAS MODERNIDADES: A CONSTITUIÇÃO DA PERSONA \\ E O MERCADO
}

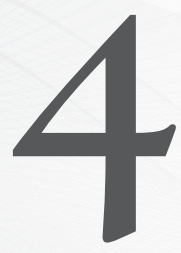

LUIz Edson FAchin

Professor Titular de Direito Civil da UFPR.

ÁreA do Direito: Civil; Constitucional; Filosofia

Autor convidado

Resumo: Partindo-se de uma análise crítica que arrosta a primeira modernidade - entendida como o legado eurocêntrico de um sistema patriarcal, codificado e arrimado em um Estado-Nação - a segunda modernidade - identificada em uma sociedade econômica regulada por leis próprias, na qual os direitos fundamentais deixaram o campo do debate da efetividade para consubstanciar um hiperconsumo das ideias destacadas da cidadania e da democracia -, buscar-se-á investigar como a complexidade do real e a mácula do aparente convivem sob uma Constituição dirigente, que proclama a emancipação do indivíduo e funda uma ordem pautada em principios democraticamente erigidos. Com isso, pretende-se demonstrar que entre os significados da equidade, democracia e direitos humanos entroniza-se a compra e venda que tudo transforma em mercadoria, fazendose premente a construção de um novo direito, pautado em novos códigos e novos discursos, estruturados em uma principiologia axiológica de indole constitucional.

Palavras-chave: Direito civil - Direito constitucional - Modernidade - Hiperconsumo - Direitos humanos.
ABSTRACT: Starting from a critical analysis of the first modernity - it's understood as the Eurocentric legacy of a patriarchal coded system, which is based on a Nation-state and the second modernity - it's identified in an economic society governed by its own laws where the fundamental rights left the arena of discussions on efficacy for a hyperconsumption of ideas divorced from good citizenship and democracy -, we will investigate how the complexity of reality and the mark of apparent live under a Constitution, which proclaims the individual emancipation and an order founded on democratic principles. Thus, we intend to demonstrate that among the meanings of equity, democracy and human rights there is a purchase and sale which transforms everything into a commodity. Nevertheless, it's urgent to build a new law, based on new codes and new discourses structured by axiological principles of constitutional nature.

KeYwords: Civil law - Constitutional law Modernity - Hyperconsumption - Human rights. 
SumÁrio: 1. Introdução - 2. A Constituição que não vimos nascer - 3. A primeira modernidade - 4. Conclusão - 5. Referências bibliográficas.

\section{InTRODUÇãO}

Partimos de uma premissa clara que marca o pensamento nos últimos séculos: a autonomia do processo econômico, como escreveu Avelãs Nunes, "não apenas em relação ao discurso metafísico, teológico ou ético, mas também relativamente ao discurso político e à lógica do poder político". 'É desse sistema da sociedade econômica regulada por leis próprias, não necessariamente da ordem jurídica, que se finca o marco zero desta reflexão.

Nasceu, por tal via, nos espaços público e privado um argentário ente fragmentado, simultaneamente conservador e inovador. Quando há declínio, ele propõe certo tipo de esperança sob a relação entre custo e benefício; à tradição, ele sugere uma emancipação liberta do passado e sem grande compromisso com o futuro; por conseguinte, ele vive o presente na lógica da utilidade e do desejo; às transformações estruturais da sociedade, ele recomenda tecnociência sem ideologia.

Várias são denominações dessa persona que se apresentou por meio de um rebanho de signos linguísticos domesticados para uma nova peregrinação, a reconstrução da vida privada.

Com ele, separou-se da política a espacialidade pública, deixaram os direitos fundamentais o campo do debate da efetividade para um hiperconsumo das ideias destacadas da cidadania e da democracia. No campo e na cidade instalou-se, então, a real Constituição dirigente: um projeto que proclama erradicar a pobreza, reduzir as desigualdades, mas não constrói searas de soberania popular nem se compromete com as garantias constitucionais e muito menos com o valor jurídico vinculante dos princípios.

Fundou-se, aí, uma segunda modernidade. E é nessa complexidade - entre o real e o aparente - que perambula um novo ícone: uma nova lei da história que se legitima precisamente naquilo que aparentemente rejeita.

No governo jurídico das relações interprivadas, de modo especial, transparece seu intento entre Códigos Civis e Constituições. Basta ler, sem rodeios, a estrutura das novas proposições legislativas centrais, do que é exemplo o Código Civil brasileiro vigente.

1. Avelãs Nunes, à p. 14 da obra Uma introdução à economia política. São Paulo: Quartier Latin, 2007. 
Diante desse espantoso tempo, nasce o desafio de compreender a oportunidade da análise do mercado e seus estatutos jurídicos, da racionalidade econômica privada no direito, da moral que se oporia à reificação da sociedade, e da suposta harmonização entre economia e justiça, entre cidadania e consumo.

Nada disso nos parece mais relevante que nos perguntarmos: como chegamos, enfim, a esse novo leito de Procusto?

\section{A CONSTItUIÇÃO QUE NÃO VIMOS NASCER}

Foi a Constituição que não vimos nascer, embora concebida por uma Nação tomada pelo ideário de mudança e de transformação em todos os horizontes que beneplacitavam uma nova cidadania, o primeiro evento que, no Brasil, marcou essa segunda modernidade.

Uma promessa se converteu em ausência, uma vez dela se fez pouco diante dos novos corpos dessa persona. Cedeu perante a nostalgia da primeira modernidade e da desconstrução das possibilidades plurais e complexas. Nela, o que de pouco Marx havia deu lugar a muito Tocqueville que nela cabia, e atomizou-se a política; comitês de sábios voltaram a dominar o conhecimento, como na bioética e as novas tecnologias; novos códigos pautaram um salto para o passado e começou o tempo dos processos sem sujeito, afinal, aí estava, então, no trânsito das coisas, bens e interesses, o corpo do direito como objeto da representação de avenças e negócios.

Ao direito, é claro, foram postas questões de legitimidade e do poder, das diversas formas de tirania, e da pessoa como objeto, mas a interrogação foi reposta no cenário pela reconstrução do direito privado à luz do modelo das codificações de outrora, higienizadas pelo saber insípido e inodoro da técnica jurídica.

Mesmo assim, ao alcance de todos ficou o imenso horizonte da função promocional do Estado como um discurso povoado pelas teses das "exclusões inclusivas", desde que sem alterações estruturais ou rupturas. E quando, em raras hipóteses, o Judiciário se vê compelido a debater questões de poder, assacam-lhe de pronto a crítica da "judicialização da política" ou, ainda, do ativismo judicial.

Ao Estado de Direito substituiu-se esse outro estado de coisas, esquecendo-se das advertências que já haviam sido feitas por José Lamartine Correa de Oliveira e Francisco Muniz em 1978, quando o Brasil se sufocava naquela outra ditadura: tudo se reduz a cinzas se a sociedade e o Estado-Governo não se subordinam ao direito e ao Estado Democrático de Direito.

As respostas a essa advertência foram destronadas. 
Na sombra tênue de uma ética que seria informada pela justiça substancial, pelos direitos fundamentais prestacionais, pela efetivação do Estado Democrático de Direito, confirmou-se a insinceridade normativa: o redesenhado sistema que se criou, se desenvolveu, ele mesmo aparentemente se aniquilou e renasceu redivivo, recolocando-se com uma face refinada e plena de moralidade, a propor, suavemente, as alavancas para fazer o País crer, enfim, que ficaria em pé, mesmo sabendo-se, na realidade, curvado em servidão.

Foram agenciadas mentes, palavras e instituições para legitimar, sob um teatral véu da cidadania política, um reconhecimento da diversidade e da pluralidade, encontrando ambiente propício numa prêt-à-porter lex mercatoria.

Como escreveu André-Jean Arnaud, a "governança" passa a ocupar o lugar da política, e coloca em cheque a filosofia moderna do direito e do Estado; agora, da antiga separação entre economia e direito, criticada por Hayek, emerge um novo princípio político do contrato social de Jean-Jacques Rousseau: ordem e eficiência. ${ }^{2}$

São as "sociedade nacionais" que estão agora desbancadas pela sociedade sem limites, pela grande sociedade, despida de preocupações com soberania, direitos individuais e outros aspectos alheios às operações da globalização.

Ao lado da debilidade na densificação do projeto constitucional, o segundo evento com tal desiderato foi a vigência em 2003 do Código Civil brasileiro.

O malogro substancial do projeto constitucional e a retomada do pathos oitocentista foram as portas de entrada para uma nova modernização conservadora no País do começo do século XXI, cujos sintomas se expressam no Estado, na sociedade e no triunfo tardio e ressignificado do patrimonialismo de Locke sobre a dignidade kantiana atravessando teoria e práxis.

Por isso, o momento é propício para debater as razões pelas quais vive o direito civil contemporâneo tempo paradoxal e de grande perplexidade. É a passagem do status ao contrato e a própria travessia inconclusa dos Códigos às Constituições que fez emergir novos avatares da vida privada nos discursos jurídicos e nos Códigos Civis contemporâneos.

Flutua esse corajoso modo de ver o governo jurídico das relações privadas nas águas de duas modernidades.

De um lado, aquela que se foi sem ter efetivamente se despedido da cena inacabada das relações sociais no Brasil, e de outra parte, esse mosaico ousado

2. À p. 19 da Introdução à obra Globalização e Direito I: impactos nacionais, regionais e transnacionais, 2. ed. Rio de Janeiro: Lumen Juris, 2005. 
que resplandece no palco atual como espaço nascente de regulação jurídica balizada por uma espécie de vale-tudo.

Expressões hoje salientes encarnam tanto permanências pautadas pelo pretérito como golden age, sustentando o inexorável afunilamento do discurso jurídico a questões internas, endógenas e intrassistemáticas, quanto reconstruções à outrance povoam o regime jurídico das titularidades, do trânsito jurídico e do projeto parental. Em suma, de uma margem, códigos encanecidos, e de outra, um novo sujeito: ambos assumem o corpo do direito que se fez persona e mercado.

\section{A PRIMEIRA MODERNIDADE}

Se agora é possível reconhecer parte desse espelho do pretérito no presente, cumpre reconhecer que o cenário da primeira modernidade não era precisamente assim.

Basta principiar com o que se elaborou a partir do século das Luzes: um ordenamento e direitos de origem romano-canônica à luz de circunstâncias políticas, históricas, econômicas e sociais que fundaram as "sociedades nacionais".

Duas paternidades deram o tom dessa primeira modernidade; no patriarcado da família, o chefe daquele modelo europeu, branco e masculino; na paternidade metafórica do Estado, a codificação civil, o ícone do apogeu do Estado-Nação.

Em essência, navegou-se pelo século XIX, sob uma concepção autoritária e dogmática da ciência; os saberes se projetavam em pretensões de universalidade e as questões do método eram todas submetidas à solução pelo conhecimento científico.

A certeza afastava o risco, a segurança se embalava nos braços da previsibilidade, e o tempo seguia linear em direção à conservação do status quo. Permanência e perenidade eram valores que oscilavam no pêndulo dos sentidos e do espaço.

No Direito, foi ali o tempo de um sujeito biografado nas codificações; na política, o renascimento das repúblicas; na economia, reivindicações para a distribuição da riqueza, para a igualdade. Ricardo e Marx chamavam a atenção da economia política, e no Direito, debates se circunscreviam às fronteiras nacionais.

Às luzes daquela engenharia das mentes, gestou uma passagem. Ocorre que ao início daquela travessia, havia, no meio do caminho, um leito de Procusto. Era o dogmatismo formal do direito privado dos Códigos oitocentistas que fazia valer, nos seus juízos estreitos e de exclusão, os bitolados limites da fattispecie. 
Como se sabe, da mitologia grega narra-se que Procusto era um salteador que vivia em uma floresta e tinha ele uma imensa cama. Assim, aqueles que por ali passavam eram aprisionados e colocados por ele em sua cama. Daqueles que eram muito grandes, maiores que a cama, Procusto cortava os pés, e daqueles que eram pequenos, Procusto os esticavam. Por conseguinte, o tamanho da cama era o padrão utilizado por Procusto.

O direito civil dogmatizante, sem abertura para a cultura jurídica, para a justiça, e para as questões sociais, utilizava a metáfora do padrão de Procusto, e assim o fazia para eliminar ou incluir as situações de fato e de direito. Não se tratava de mera técnica, era, sim, um suplício bárbaro sobre a vida, para que a própria vida se adaptasse ao leito da forma.

Para dar fim a Procusto, o clamor popular fez emergir à cena Teseu, lutador que havia recuperado a espada e as sandálias que haviam pertencido a Egeu, seu pai. Teseu se pôs a caminho e não só derrotou Procusto como lhe tomou as armas. A realidade rebelou-se contra o artificial mundo dos conceitos.

Características embalavam esse soi-disant novo sonho: a troca da certeza pelo risco, a recusa da autoridade absoluta, a inexistência de modelos apriorísticos, e o nascimento jurídico do sujeito de necessidades.

A metáfora ainda presente de Teseu é a simbólica passagem da Carta Política de então que se converteu na tábua promissora da emancipação dos sentidos.

Não era mesmo assim o tempo de então. Havia, no então direito moderno, o limite exegético das codificações que se prestava a compromissos de totalidade e de completude, submetendo a juízos apriorísticos os fatos e a própria dinâmica da vida, submissa aos preceitos codificados.

A superação daquele legado do positivismo científico teria transitado para a contemporaneidade vincada pela incidência dos direitos fundamentais nas relações interprivadas, pela interpenetração dos espaços público e privado, entre outros elementos que teriam fundado um locus diferenciado de compreensão e formulação das situações jurídicas existenciais e patrimoniais.

Porém, no meio do caminho, havia mais que uma pedra.

Entre as duas margens o ponto mais profundo não sonegou ao presente a vocação que permeia uma sociedade de classes. Por isso, hoje uma aliança sutil abraça o que entre essas duas modernidades se fez percurso. Recolocou-se na travessia um novo leito de Procusto, agora não mais na cultura, no direito ou na política, mas sim na economia. Repita-se: o primado dos padrões sobre a essência é só operação econômica, vale dizer, era e agora mais que antes se confirmou, como escrevera Avelãs Nunes, a própria capacidade de concreta ação normativa do mercado. 
É evidente que uma Constituição se faz Constituição no desenrolar de um processo constituinte material de índole permanente. Ações afirmativas, acesso a bens de um mínimo existencial digno, resgate de dívidas históricas, são exemplos desse proceder.

Entretanto, o cômputo da compreensão plural do mercado deve ser feito como aquele gerado na economia pela EC 6/1995, a qual revela, no Brasil, o balanço real e efetivo; tal emenda, como se sabe, permitiu que a pesquisa e a lavra de recursos minerais e o aproveitamento dos potenciais efetuados mediante autorização ou concessão da União, por brasileiros ou empresa constituída sob as leis brasileiras e que tenha sua sede e administração no País, na forma da lei, cabendo serem levadas a efeito em faixa de fronteira ou terras indígenas.

Vê-se com clareza, por conseguinte, de qual pessoa se trata quando se elucida essa bem acabada lógica dos fatores materiais de produção da vida e da própria história.

\section{CONCLUSÃO}

Seria criticável arrematar sem registrar que segmentos da literatura sobre o direito civil de hoje, faz algum tempo se colocaram em marcha, peregrinando pelos recônditos tenebrosos da cegueira dogmática até fazer emergir, acima dos conceitos, o mundo dos fatos, criador e construtivo, aberto para as luzes emancipatórias do contemporâneo.

Se "as pretensões e a cobiça povoam e valorizam territórios desertos", e "tudo o que existe constitui uma perspectiva de valor", ainda assim, esse mundo novo abre possibilidade porque é diversificado e pode propiciar a cada lugar, quiçá, como afirmou Milton Santos, "a comunhão universal com todos os outros". ${ }^{3}$

Isso, nada obstante, não foi e nem é suficiente. A resposta foi almejada sob uma principiologia axiológica de índole constitucional. E nela tais questionamentos encontraram abrigo, mas não o satisfatório.

É certo que hoje, o país respira, ao menos politicamente, democracia, e por isso mesmo se deve conservar e relembrar as lições segundo as quais não há verdadeiro direito se não existir, no plano concreto, a respectiva tutela.

Entre os significados da equidade, democracia e direitos humanos entroniza-se, todavia, a compra e venda que tudo transforma em mercadoria, mediante uma ordem jurídica que altera a cogência pela negociação, afasta o Estado-

3. À p. 173 da obra Por uma outra globalização: do pensamento único à consciência universal. Rio de Janeiro: Record, 2000. 
-legislador do centro dos poderes e intenta limitar o Estado-juiz a retomar-se como bouche de la loi; a espacialidade pública cede lugar para a regulação; finanças e moeda constituem o controle da economia que faz movimentar, entre sístoles e diástoles, o Estado e a sociedade detentores dos bens de produção.

Para tanto, são necessários novos códigos e novos discursos, especialmente nas faculdades de direito. São necessários instrumentos, linguagem e comunicação que opere com esses valores, e a tarefa se mostra urgente.

Como em boa época já se escreveu sobre essa ordem jurídica: "tem o seu fundamento na destruição do estatuto de apoliticismo da economia, isto é, na sua transformação em objecto de prática política", e o direito é aí chamado para o efeito da regulação; desde o capitalismo industrial a economia deixa de estar fora do domínio do sistema jurídico-político, e esse processo desemboca na representação econômica e jurídica do mercado. ${ }^{4}$

Nada obstante, tal como Teseu ao enfrentar Procusto, parece-nos que é preciso reconhecer como vem suave, feito um soft law simbólico, esse vento de uma dogmática refinada e sensível.

Aos que já sucumbiram e saúdam o fim da história, enfim, aos novos oitocentistas do século XXI, permito-me lembrá-los dos versos de Manuel Alegre:

"Mesmo na noite mais triste

Em tempo de servidão

Há sempre alguém que resiste

Há sempre alguém que diz não."

\section{REFERÊNCIAS BIBLIOGRÁFICAS}

Arnaud, André-Jean. O Direito traído pela filosofia. Porto Alegre: Fabris, 1991. . Globalização e Direito I: impactos nacionais, regionais e transnacionais. 2. ed. Rio de Janeiro: Lumen Juris, 2005.

Avelãs Nunes, António José. Uma introdução à economia política. São Paulo: Quartier Latin, 2007.

Carbonnier, Jean. Flexible droit: pour une sociologie du droit sans riguer. 9. ed. Paris: LGDJ, 1998.

Carvalho, Orlando de. A teoria geral da relação jurídica - Seu sentido e limites. Nota prévia. Para uma teoria geral da relação jurídica civil. 2. ed. Coimbra: Centelha, 1981. vol. 1.

4. Vital Moreira, à p. 99 da obra A ordem jurídica do capitalismo. 4. ed. Lisboa: Caminho, 1987. 
FACHIN, Luiz Edson. Limites e possibilidades da nova teoria geral do direito civil. Revista Jurisprudência Brasileira. n. 172. p. 45-54. Curitiba: Juruá, 1994.

FrancesChelli, Vincenzo. I rapporti di fato. Milano: Giuffrè, 1984.

GILISSEN, John. Introdução histórica ao Direito. Lisboa: Calouste Gulbenkian, 1975.

Miaille, Michel. Introdução crítica ao Direito. 2. ed. Lisboa: Estampa, 1989.

Moreira, Vital. A ordem jurídica do capitalismo. 4. ed. Lisboa: Caminho, 1987.

Morin, Edgar. O paradigma perdido: a natureza humana. 4. ed. Mira-Sintra/Portugal: Europa-América, 1988.

Perlingieri, Pietro. Perfis do direito civil. Rio de Janeiro: Renovar, 1997.

SAldanha, Nelson. O jardim e a praça: ensaio sobre o lado privado e o lado público da vida social e histórica. São Paulo: USP, 1993.

SAntos, Milton. Por uma outra globalização: do pensamento único à consciência universal. Rio de Janeiro: Record, 2000.

SERres, Michel. O contrato natural. Rio de Janeiro: Nova Fronteira, 1991.

Tepedino, Gustavo. Contornos constitucionais da propriedade privada. In: DiReito, Carlos Alberto Menezes. Estudos em homenagem ao Professor Caio Tácito. Rio de Janeiro: Renovar, 1997.

Tepedino, Maria Celina B. M. A caminho de um direito civil constitucional. Revista de Direito Civil. n. 65. p. 21-32. São Paulo: Ed. RT, jul.-set. 1993.

Villey, Michel. En torno al contrato, la propiedad y la obligación. Buenos Aires: Ghersi, 1980.

Wieacker, Franz. História do direito privado moderno. 2. ed. Lisboa: Calouste Gulbenkian, 1993.

Wolkmer, Antonio Carlos. Pluralismo jurídico: fundamentos de uma nova cultura no direito. São Paulo: Alfa-Omega, 1994.

\section{Pesouisas do EditORIAL}

\section{Veja também do mesmo Autor}

- A cidade nuclear e o direito periférico (reflexões sobre a propriedade urbana), de Luiz Edson Fachin - RT 723/107;

- A reforma no direito brasileiro: novas notas sobre um velho debate no direito civil, de Luiz Edson Fachin - RT 757/64;

- Aspectos jurídicos da união de pessoas do mesmo sexo, de Luiz Edson Fachin - RT 732/47;

- Coisa julgada no processo cautelar, de Luiz Edson Fachin - RePro 49/43;

- Contratos e ordem pública, de Luiz Edson Fachin - RDB 37/339; 
- Contratos e responsabilidade civil: duas funcionalizações e seus traços, de Luiz Edson Fachin - RT 903/26;

- Da propriedade como conceito jurídico, de Luiz Edson Fachin - RT 621/16;

- 0 estatuto civil da clausura real, Luiz Edson Fachin - RT721/49;

- Reivindicação - Improcedência, de Luiz Edson Fachin - RePro 27/254;

- Reivindicação - Posse justa - Inadmissibilidade, de Luiz Edson Fachin - RePro 35/277; e

- Terras devolutas e a questão agrária brasileira - Anotações preliminares para um ensaio, de Luiz Edson Fachin - RT629/52. 